\title{
Highly efficient enzymatic catalysis for cyclocarbonate polymerization
}

\author{
Xiao-hua Luo, Jun Feng, Hua-fen Wang, Wei Su, Xian-zheng Zhang and Ren-xi Zhuo \\ In this study, we developed a metal-free biosynthetic strategy of enzymatic polymerization to fabricate aliphatic \\ poly(pentamethylene carbonate) (PPMC). Novozym-435 lipase showed considerably high catalytic efficiency, and high \\ molecular weights $\left(M_{\mathrm{n}}\right)$ of up to $6.0 \times 10^{4} \mathrm{~g} \mathrm{~mol}^{-1}$ were readily achieved through the ring-opening polymerization of \\ cyclobis(pentamethylene carbonate). The reaction parameters, including monomer concentration and lipase concentration, were \\ examined. It seemed that little polymer degradation occurred during the polymerization, which would happen in the case of \\ organometallic catalysis. In vitro enzymatic degradation tests indicate that the carbonate groups may not be sensitive to \\ catalysis from the lipases of porcine pancreas and Candida rugosa (AYS). PPMC was found to possess higher flexibility and \\ tenacity, relative to poly(trimethylene carbonate). Thermogravimetrical analyses suggest that the chemical structure of \\ poly(alkylene carbonate)s exerts a significant influence on their thermal stability and decomposition mechanism. \\ Polymer Journal (2010) 42, 722-727; doi:10.1038/pj.2010.69; published online 4 August 2010
}

Keywords: degradation; Novozym-435 lipase; poly(pentamethylene carbonate); ring-opening polymerization; thermal decomposition

\section{INTRODUCTION}

Aliphatic polyesters are important synthetic biomaterials because of their excellent biocompatibility and biodegradability. ${ }^{1-5}$ These polymers have been widely explored as drug delivery vehicles and tissue engineering matrices. Compared with polyesters, aliphatic polycarbonates degrade without the generation of acidic compounds. ${ }^{6-8}$ This feature is especially attractive for in vivo applications because the acidic microenvironment caused by polyester degradation might induce pronounced inflammatory response ${ }^{9}$ or deactivate the drugs encapsulated in the polymeric carriers. ${ }^{10}$ Moreover, polycarbonates degrade in a surface-erosion manner and are much less prone to degradation than polyesters, which is advantageous in applications in which relatively high stability is desired. ${ }^{6}$ Therefore, aliphatic polycarbonates show great promise as medical materials for in vivo application. Indeed, copolymers of cyclic trimethylene carbonate (TMC) with D,L-lactide or $\varepsilon$-caprolactone have been used in clinical application.

Ring-opening polymerization (ROP) is a well-established method for the fabrication of polyesters/polycarbonates with predictable molecular weights $\left(M_{\mathrm{n}}\right)$ and narrow $M_{\mathrm{n}}$ distributions. Through a rational design of ROP initiators, well-defined polymer architectures and specific functions can be readily realized. ${ }^{5,11,12}$ In contrast, the control afforded by the polycondensation method is remarkably limited. Currently, the most frequently used catalysts for ROP are organometallic compounds. Safety remains a major concern when the synthesized materials are used in vivo. The organometallic residue is difficult to remove and, consequently, can cause latent toxicity in cells and organs. Biosynthetic pathways such as enzymatic ROP have thus attracted increasing attention as a new trend in biodegradable polymer synthesis. ${ }^{13-16}$

Adjusting the main-chain structure is one of the conventional ways to obtain polymer materials with versatile properties. Up to now, almost all available lactones have been enzymatically polymerized from 4-membered propiolactone to 17-membered hexadecanolide to fabricate aliphatic polyesters with different chain lengths. ${ }^{12-16}$ Enzymatic catalysis has thus far proved to be advantageous compared with chemical preparative routes for the ROP of large lactones in terms of efficiency. ${ }^{17,18}$ A variety of new materials with suitable biochemical and physical properties can be readily generated by enzymatic copolymerization of different lactones. ${ }^{19}$ In comparison, related studies on enzymatic ROP of cyclocarbonates are almost always focused on six-membered TMC and its analogs. ${ }^{20,21}$ To meet various practical demands, more research needs to be conducted into the fabrication of polycarbonates with longer chain lengths. However, research thus far has been limited to PTeMC, PHMC and PDMC derived from 1,4-butanediol, 1,6-hexanediol and 1,10-decanediol, respectively. $^{22-25}$

Our group recently reported the preparation of poly(pentamethylene carbonate) (PPMC) by $\mathrm{Sn}(\mathrm{Oct})_{2}$-catalyzed ROP of cyclobis(pentamethylene carbonate) (PMC) ${ }_{2} \cdot{ }^{26}$ An interesting odd-even effect was observed in relation to the number of $\mathrm{CH}_{2}$ groups per $-\left(\mathrm{CH}_{2}\right)_{\mathrm{n}}$ OCOO- repeat unit $\left(\mathrm{Num}_{\mathrm{c}}\right)$ of polycarbonates. PPMC was found to possess much lower crystallization capability than the reported polycarbonates, except for amorphous PTMC. This special property

Key Laboratory of Biomedical Polymers of Ministry of Education, Department of Chemistry, Wuhan University, Wuhan, PR China 


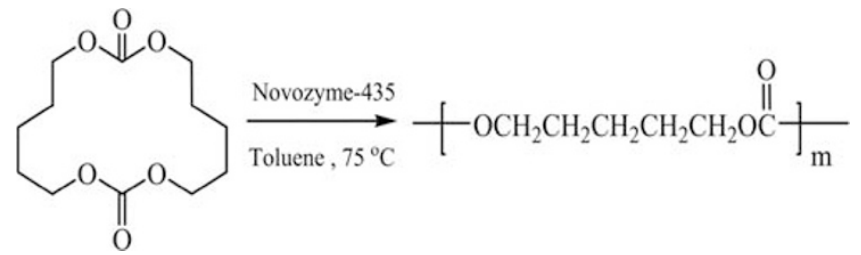

Scheme 1 Synthesis of PPMC by enzymatic ring-opening polymerization of $(\mathrm{PMC})_{2}$.

may endow PPMC with great potential for medical applications, in addition to applications in the plastics industry. It may be used to develop soft materials for tissue engineering and as an efficient reservoir for hydrophobic drugs. However, recent studies have shown that $\mathrm{Sn}(\mathrm{Oct})_{2}$ used in PPMC preparation has a toxic effect on cells and can accumulate in the body. ${ }^{27}$ In this work, we attempted metal-free enzymatic ROP for PPMC synthesis to decrease exogenous damage to a great extent (Scheme 1). We found that an immobilized lipase from Candida antarctica (Novozym-435) exhibited attractively high catalytic efficiency, as demonstrated by the high $M_{\mathrm{n}}$ of up to $6.0 \times 10^{4} \mathrm{~g} \mathrm{~mol}^{-1}$ obtained. At present, the low catalytic efficiency is known to be the main limitation for the industrialization of enzyme catalysis. Another aim of this work was to broaden the research scope regarding enzymatic ROP of cyclocarbonates. Furthermore, the enzymatic degradation behaviors of PPMC, as well as its mechanical properties and thermal stability, were also examined.

\section{EXPERIMENTAL PROCEDURE}

\section{Materials}

Toluene was dried over Na/K alloy and distilled. 1,5-Pentanediol was purchased from Fluka (Sigma-Aldrich Trading Co., Ltd., Shanghai, China) and used as received. Diethyl carbonate was of chemical grade from Beijing Chemical Reagent (Beijing, China) and was distilled before use. Novozym 435, an immobilized lipase (lipase B) from Candida antarctica, was purchased from Sigma-Aldrich Trading Co., Ltd. Lipases from porcine pancreas (PPL) and from Candida rugosa (AYS) were also purchased from Sigma.

\section{Instruments}

Melting point determinations were performed on a microscopic $(20 \times 10)$ melting-point apparatus and were uncorrected. Infrared spectra were recorded on a PerkinElmer-2 spectrometer (PerkinElmer Inc., Shanghai, China). Samples were either film-cast in chloroform onto sodium chloride plates or pressed into potassium bromide $(\mathrm{KBr})$ pellets. ${ }^{1} \mathrm{H}$ NMR spectra were recorded in a solution of $\mathrm{CDCl}_{3}$ on a Varian Mercury-VX 300 apparatus (Varian Inc., Palo Alto, CA, USA) with TMS as an internal standard. Gel-permeation chromatography was carried out on a Waters HPLC system (Waters Inc., Shanghai, China) equipped with a Model 2690D separation module, a Module 2410 differential refractive index detector and a Shodex K803 column (Waters Inc.). Chloroform was used as an eluent with a flow rate of $1.0 \mathrm{ml} \mathrm{min}^{-1}$. Waters MILLIENIUM32 module software was used to calculate $M_{\mathrm{n}}$ on the basis of a universal calibration curve generated by narrow $M_{\mathrm{n}}$ distribution polystyrene standards. The sample concentration and injection volume were $0.3 \%$ (wt/v) and $20 \mu \mathrm{l}$, respectively.

\section{Synthesis of dimeric $(\mathrm{PMC})_{2}$}

Cyclocarbonate (PMC) $)_{2}$ derived from 1,5-pentanediol was synthesized as described in literature. ${ }^{26}$ The thermally decomposed crude product was washed with cold methanol $\left(-10^{\circ} \mathrm{C}\right)$. The solid residue was then recrystallized from ethyl acetate twice to isolate the product. Melting point $119-120^{\circ} \mathrm{C}$. Infrared: $v=1744 \mathrm{~cm}^{-1}(\mathrm{C}=\mathrm{O}) .{ }^{1} \mathrm{H}$ NMR $\left(\mathrm{CDCl}_{3}\right): \delta=4.21-4.26\left(\mathrm{t}, \mathrm{OCH}_{2}, 4 \mathrm{H}\right), 1.65-$ $1.68\left(\mathrm{~m}, \mathrm{OCH}_{2} \mathrm{CH}_{2}, 4 \mathrm{H}\right), 1.47-1.52\left(\mathrm{~m}, \mathrm{OCH}_{2} \mathrm{CH}_{2} \underline{\mathrm{CH}}_{2}, 2 \overline{\mathrm{H}}\right) ;{ }^{13} \mathrm{C} \mathrm{NMR}$ $\left(\mathrm{CDCl}_{3}\right): \delta=155.5(\underline{\mathrm{CO}}), \quad 67.8 \quad\left(\mathrm{OCH}_{2} \mathrm{CH}_{2}\right), 29.8 \quad\left(\mathrm{OCH}_{2} \mathrm{CH}_{2} \mathrm{CH}_{2}\right), 22.4$ $\left(\mathrm{OCH}_{2} \mathrm{CH}_{2} \mathrm{CH}_{2}\right)$.

\section{Lipase-catalyzed polymerization of $(\mathrm{PMC})_{2}$}

All reactions were conducted in toluene at $75^{\circ} \mathrm{C}$. The monomer $(\mathrm{PMC})_{2}$ and lipase were dried ( $40 \mathrm{~Pa}, 24 \mathrm{~h}$, room temperature) with phosphorus pentoxide as a desiccant before use. A typical preparation of PPMC was carried out in the following manner: A mixture of (PMC $)_{2}$ and Novozym-435 lipase was introduced into a dried glass flask. The vessel was vacuumed and purged with argon several times. Fresh toluene was then added to the flask by syringe, closed with a glass stopper and immersed in an oil bath at $75^{\circ} \mathrm{C}$. After a period of time, the resulting reaction mixture was dissolved in dichloromethane and filtered to remove the insoluble lipase enzyme. The solvents were then removed under reduced pressure to obtain crude products. The products without any treatment were dissolved in a predetermined amount of $\mathrm{CHCl}_{3}(0.3 \%(\mathrm{wt} / \mathrm{v}))$ and directly underwent gel-permeation chromatography measurement to determine the monomer conversion in addition to $M_{\mathrm{n}}$ and polydispersity because the HNMR spectra of the (PMC) $)_{2}$ monomer and corresponding polymer exhibited no distinguishable differences.

For infrared and NMR analyses, polymers were purified by pouring the polymer solution in $\mathrm{CH}_{2} \mathrm{Cl}_{2}$ into excessive menthol and drying in vacuo to constant weight. Infrared: $v=1743 \mathrm{~cm}^{-1}(\mathrm{C}=\mathrm{O}) .{ }^{1} \mathrm{H}$ NMR $\left(\mathrm{CDCl}_{3}\right): \delta=4.11-$ $4.20\left(\mathrm{t}, \mathrm{OCH}_{2}, 4 \mathrm{H}\right), 1.65-1.75\left(\mathrm{~m}, \mathrm{OCH}_{2} \mathrm{CH}_{2}, 4 \mathrm{H}\right), 1.41-1.52\left(\mathrm{~m}, \mathrm{OCH}_{2} \mathrm{CH}_{2} \mathrm{C}\right.$ $\left.\underline{\mathbf{H}}_{2}, 2 \mathrm{H}\right),{ }^{13} \mathrm{C} \quad \mathrm{NMR}\left(\mathrm{CDCl}_{3}\right): \delta=155.5(\underline{\mathrm{CO}}), 67.8 \quad\left(\mathrm{OCH}_{2} \mathrm{CH}_{2}\right), \quad 29.5$ $\left(\mathrm{OCH}_{2} \underline{\mathrm{CH}}_{2} \mathrm{CH}_{2}\right), 22.5\left(\mathrm{OCH}_{2} \mathrm{CH}_{2} \mathrm{CH}_{2}\right)$.

\section{Degradation test}

For degradation tests, round samples were prepared by compression molding using $\sim 100 \mathrm{mg}$ of polymer. Degradation was performed in $0.5 \mathrm{ml}$ phosphate $(0.02 \mathrm{M})$ buffer solution at $\mathrm{pH} 7.4$ and $37^{\circ} \mathrm{C}$ with gentle shaking. A powdery enzyme of PPL or AYS was introduced into $10 \mathrm{mg} \mathrm{ml}^{-1}$ phosphate-buffered saline. After a predetermined interval, the sample was rinsed with distilled water and then dried in vacuum at $25^{\circ} \mathrm{C}$ to a constant weight. The degradation rate was determined by the weight loss of the polymer.

\section{Thermogravimetrical analyses}

Thermogravimetrical analyses (TGA) were conducted with TGA-50 (Shimadzu, Kyoto, Japan) in the range $25-650{ }^{\circ} \mathrm{C}$ at a heating rate of $10^{\circ} \mathrm{C} \mathrm{min}^{-1}$.

\section{Mechanical properties test}

The mechanical properties test was carried out by compression in a mold at $60{ }^{\circ} \mathrm{C}$ for $5 \mathrm{~min}$ under a pressure of $100 \mathrm{~kg} \mathrm{~cm}^{-2}$. The sample size was $20 \mathrm{~mm}$ in length, $10 \mathrm{~mm}$ in width and $1 \mathrm{~mm}$ in thickness.

\section{RESULTS AND DISCUSSION}

\section{Enzymatic preparation of PPMC}

The ability of enzymes to accept cyclic carbonates as substrates has been demonstrated in the lipase-catalyzed ROP of TMC. ${ }^{20,21,28}$ In this work, all polymerizations were carried out in toluene solution at $75^{\circ} \mathrm{C}$, which has been shown to be a desirable condition with respect to Novozym-435 catalytic activity for polyester synthesis. A blank control experiment showed that no polymerization occurred without the catalyst. As reported, TMC is susceptible to spontaneous thermal polymerization. ${ }^{29}$ Larger-sized cyclocarbonates exhibited better thermodynamic stability, possibly because of the lowering of ring strain. In the presence of Novozym-435, a high $M_{\mathrm{n}}$ and monomer conversion could readily be achieved in the polymerization of $(\mathrm{PMC})_{2}$. This observation suggested that Novozym-435 catalysis was an indispensable factor in polymerization. On the other hand, lipases from porcine pancreas and Candida antarctica exhibited no or very little catalytic activity under the same conditions. In contrast, high catalytic efficiency for TMC polymerization was shown for all three lipases. ${ }^{30}$ It was reckoned that the concurrent thermal polymerization of TMC was responsible for this marked deviation.

The structure of the obtained PPMC was verified by NMR analysis, as shown in Figure 1. The characteristic resonance from PPMC can be clearly observed. A triplex signal at around 3.6 p.p.m. can be ascribed 


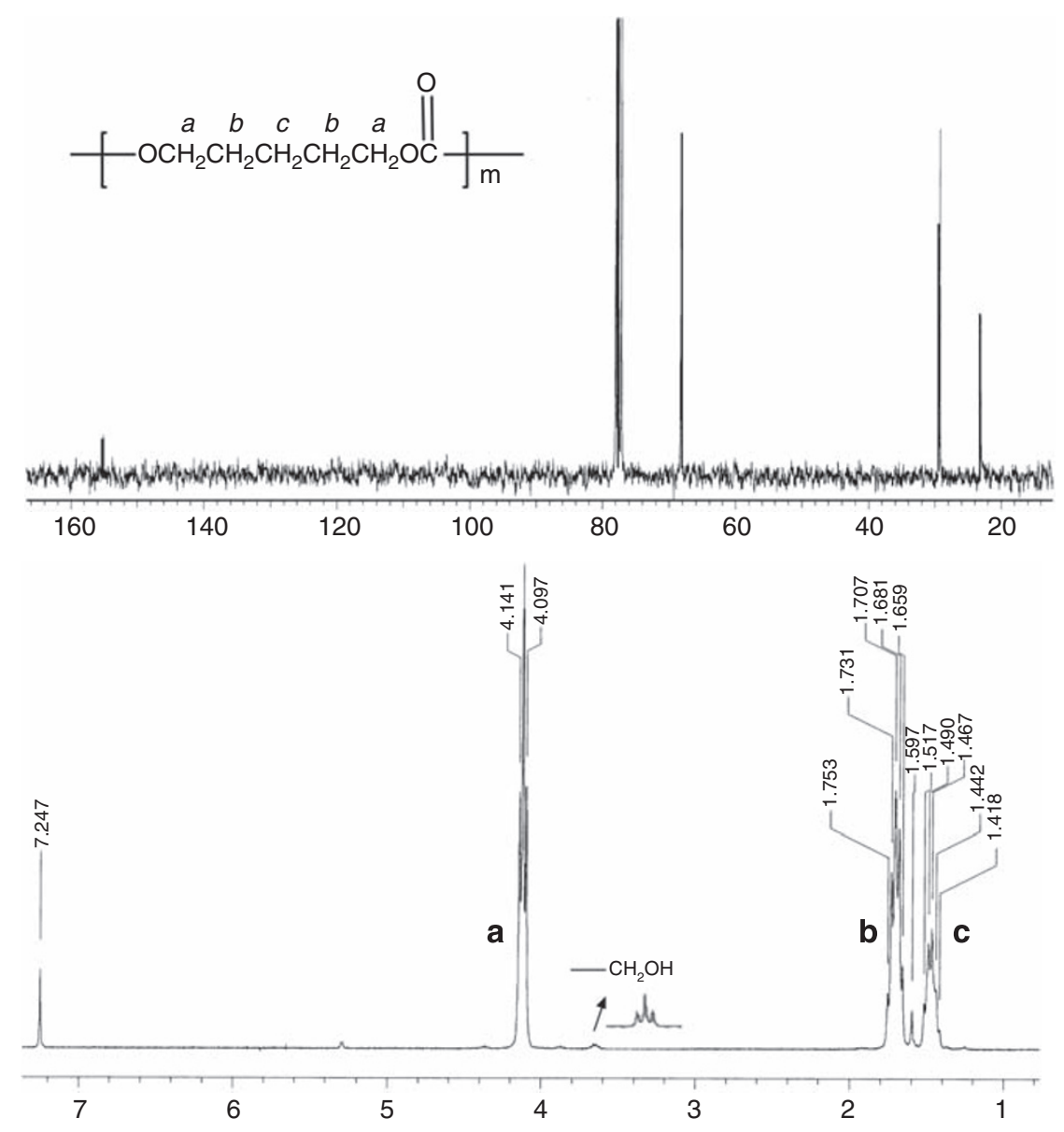

Figure $1{ }^{13} \mathrm{C}$ NMR and ${ }^{1} \mathrm{H}$ NMR spectra of PPMC precipitated in methanol.

to the methylene group $-\mathrm{CH}_{2} \mathrm{OH}$ connected to the terminal hydroxyl group in the PPMC chain. This observation is consistent with reported findings of the enzymatic ROP of TMC and $\varepsilon$-caprolactone. ${ }^{20}$ The polymerization of cyclocarbonates sometimes involves partial decarboxylation, affording poly(alkylene ether-carbonate) with a significant content of ether units. ${ }^{31,32}$ Herein, the NMR spectrum of PPMC showed that relatively little decarboxylation occurred, as hardly any signal of the ether group could be detected.

The influence of enzyme concentration was investigated during the 48-h polymerization, and the resultant data are collected in Table 1. Results indicate that there existed an optimal enzyme concentration at around $2 \%$ to achieve relatively high $M_{\mathrm{n}}$ and monomer consumption simultaneously. Under such conditions, polymers with $M_{\mathrm{n}}$ of $6.0 \times 10^{4} \mathrm{~g} \mathrm{~mol}^{-1}$ and $90 \%$ conversion were achieved. Beyond this optimal concentration, $M_{\mathrm{n}}$ declined as enzyme concentration increased. In contrast, the monomer conversion did not change significantly. This result can be understood by considering the mechanism for enzymatic ROP of lactones. The water inherently contained in the enzyme would be partially released and served as the initiator. ${ }^{20,30}$ Therefore, more polymer chains would be generated with increasing enzyme concentration, leading to a reduction in $M_{\mathrm{n}}$ of the resulting polymer.

Another series of polymerizations was conducted over $48 \mathrm{~h}$ in such a way that the amount of enzyme and monomer was fixed and the toluene/monomer ratio was varied (Table 2). Interestingly, the solventless polymerization (ratio of $0: 1$ ) occurred at $75^{\circ} \mathrm{C}$, which is much
Table 1 Conditions and results of Novozym-435-catalyzed polymerization of $(\mathrm{PMC})_{2}$ with different enzyme concentrations ${ }^{\mathrm{a}}$

\begin{tabular}{lcccc}
\hline Entry & $\begin{array}{c}\text { Enzyme } \\
\text { concentration }^{\mathrm{b}}\end{array}$ & $\begin{array}{c}M_{n} \times 10^{-4} \\
\left(\mathrm{gmol}^{-1}\right)^{\mathrm{c}}\end{array}$ & $M_{w} / M_{n}{ }^{\mathrm{c}}$ & $\begin{array}{c}\text { Conversion } \\
(\%)^{\mathrm{c}}\end{array}$ \\
\hline 1 & 0 & - & - & - \\
2 & $0.5 \%$ & 4.42 & 1.60 & 71 \\
3 & $2 \%$ & 6.44 & 1.38 & 90 \\
4 & $5 \%$ & 4.52 & 1.46 & 93 \\
5 & $8 \%$ & 3.54 & 1.64 & 96 \\
6 & $10 \%$ & 3.09 & 1.73 & 96 \\
\hline
\end{tabular}

aAll reactions were carried out in $0.4 \mathrm{ml}$ toluene at $75^{\circ} \mathrm{C}$ over $48 \mathrm{~h}$ with $0.1 \mathrm{~g}(\mathrm{PMC})_{2}$. bWeight ratio of lipase/monomer.

cDetermined by gel-permeation chromatography using $\mathrm{CHCl}_{3}$ as eluent.

lower than the melting point of $(\mathrm{PMC})_{2}$. A product with $M_{\mathrm{n}}$ of $2.81 \times 10^{4} \mathrm{~g} \mathrm{~mol}^{-1}$ and $50 \%$ conversion was obtained (Table 2, entry 1 ). Such a phenomenon, similar to solid-phase polymerization, has previously been reported in the lipase-catalyzed polymerization of lactide and cyclobis (decamethylene carbonate), as well as in spontaneous thermal polymerization of macrocyclic aromatic carbonates. $^{23,33,34}$ Although we cannot provide an exact explanation at present, the results revealed the high affinity of Novozym- 435 for the $(\mathrm{PMC})_{2}$ substrate. Compared with solventless polymerization, the addition of toluene resulted in quantitative monomer conversion in 
all parallel experiments because of the lowered system viscosity. An evident declining trend in $M_{\mathrm{n}}$ with increasing toluene/carbonate ratio was observed. This trend could be due to the increasing amount of trace water that inevitably accompanied toluene addition.

The time course of the polymerization reaction was also investigated. A mixture of $0.01 \mathrm{~g}$ Novozym- 435 and $1 \mathrm{~g}(\mathrm{PMC})_{2}$ in $4 \mathrm{ml}$ toluene was heated at $75^{\circ} \mathrm{C}$. It was found that the monomer was consumed rapidly at the initial stage. When monomer consumption reached above $60 \%$, the growth tended to slow down (Figure 2a). To investigate the polymerization mechanism, a plot of $\operatorname{Ln}[\mathrm{Mo}] /[\mathrm{Mt}]$ was constructed (Figure $2 \mathrm{~b}$ ) as a function of reaction time. The correlation coefficient $\left(R^{2}\right)$ from linear regression analysis of the plot was determined to be 0.992 , indicating linearity. This result suggests that few chain terminations occurred and that monomer consumption might follow a first-order rate law. The polymerization seemed to assume some features of living polymerization at the given condition. However, the polydispersity index $\left(M_{\mathrm{w}} / M_{\mathrm{n}}\right)$ determined from gel-permeation chromatography measurement was greater than unity, which seems contrary to what is expected from living polymerization. This deviation can possibly be attributed to the bimolecular exchange (transesterification) due to the reversible nature of enzymatic reactions. ${ }^{13}$ Similar results have previously been described in the pseudo-living polymerization of $\varepsilon$-caprolactone catalyzed by $\mathrm{Sn}(\mathrm{Oct})_{2}$, which would also catalyze both ROP and transesterification. ${ }^{35}$ Meanwhile, the hydrolysis degradation may sometimes become prominent at a later stage in the ring-opening synthesis of polyester, ${ }^{36}$ which was thought to be a main factor leading to deviation from living polymerization. In this study, we designed a 4-day experiment to

Table 2 Conditions and results of Novozym-435-catalyzed polymerization of $(\mathrm{PMC})_{2}$ with different monomer concentrations ${ }^{\mathrm{a}}$

\begin{tabular}{lcccc}
\hline Entry & $\begin{array}{c}\text { Monomer } \\
\text { concentration }^{\mathrm{b}}\end{array}$ & $\begin{array}{c}M_{n} \times 10^{-4} \\
(\mathrm{gmol})^{-1}\end{array}$ & $M_{w} / M_{n}{ }^{\mathrm{c}}$ & $\begin{array}{c}\text { Conversion } \\
(\%)^{\mathrm{c}}\end{array}$ \\
\hline 1 & $0: 1$ & 2.81 & 1.91 & 50 \\
2 & $5: 1$ & 5.76 & 1.43 & 98 \\
3 & $6: 1$ & 4.22 & 1.40 & 98 \\
4 & $8: 1$ & 1.97 & 1.45 & 99 \\
5 & $10: 1$ & 1.69 & 1.45 & 98 \\
\hline
\end{tabular}

${ }^{a}$ All reactions were carried out in toluene at $75^{\circ} \mathrm{C}$ over $48 \mathrm{~h}$ with $0.1 \mathrm{~g}(\mathrm{PMC})_{2}$. The weight ratio of lipase to monomer was fixed at $1: 100$

of lipase to monomer was fixed at $1: 100$.
b Ratio of toluene to monomer $(\mathrm{vol}(\mathrm{ml}) / \mathrm{wt}(\mathrm{g})$

'Determined by gel-permeation chromatography using $\mathrm{CHCl}_{3}$ as eluent.

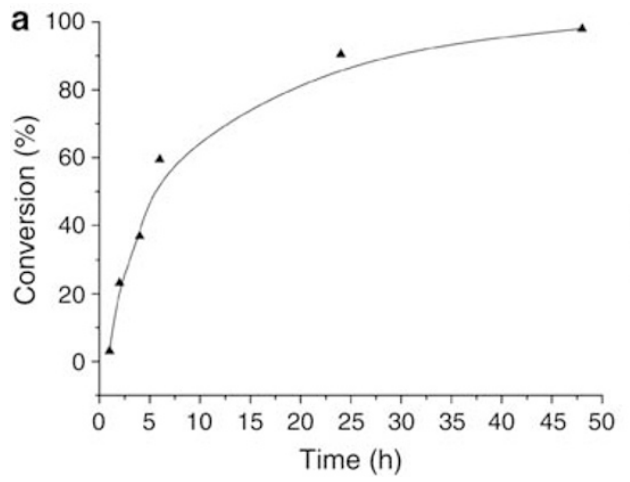

explore the reaction process with respect to the changes in $M_{\mathrm{n}}, M_{\mathrm{w}} / M_{\mathrm{n}}$ and monomer conversion. After the monomer was almost completely consumed, insignificant changes during polymerization were detected. For example, under the same conditions used in obtaining data for entry 2 in Table 2 , the $M_{\mathrm{n}}$ values measured after 24,72 and 96-h reactions were $6.00,6.08$ and $6.20 \times 10^{4} \mathrm{~g} \mathrm{~mol}^{-1}$, respectively. This result shows that little hydrolysis degradation occurred.

\section{Properties of PPMC}

The mechanical properties of the PPMC sample $\left(M_{\mathrm{n}}=3.04 \times\right.$ $10^{4} \mathrm{~g} \mathrm{~mol}^{-1}$ ) were tested. The tensile strength and elongation at break were determined to be $1.5 \mathrm{~kg} \mathrm{~cm}^{-2}$ and $500 \%$, respectively. In comparison, PTMC with a similar $M_{\mathrm{n}}$ had been reported to have a higher tensile strength of $5 \mathrm{~kg} \mathrm{~cm}^{-2}$ and a lower elongation at break of $160 \% .{ }^{37}$ The difference in mechanical properties could be attributed to the fact that polymers containing longer aliphatic chains are more flexible. It is reflected in the lower glass transition temperature $\left(T_{\mathrm{g}}=-39^{\circ} \mathrm{C}\right)$ of PPMC relative to that of PTMC $\left(T_{\mathrm{g}}=-15^{\circ} \mathrm{C}\right) .{ }^{26}$

The thermal stability of poly(alkylene carbonate)s was investigated on the basis of TGA measurements. The TGA thermogram of this polymer is shown in Figure 3. The thermogram showed that the thermal decomposition of PPMC began at around $250{ }^{\circ} \mathrm{C}$ and reached its maximum rate at around $320^{\circ} \mathrm{C}$. The decomposition was completed at approximately $330-340^{\circ} \mathrm{C}$. As can be seen from the thermo-

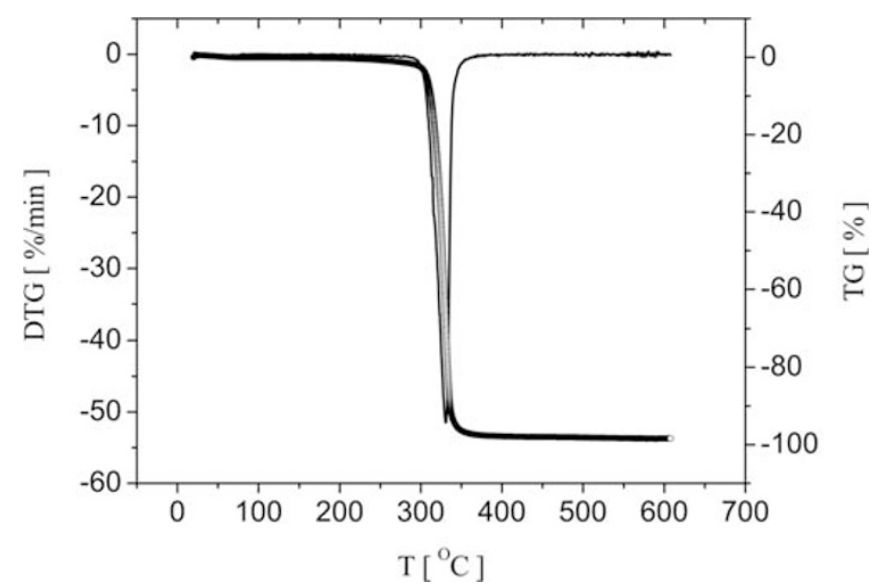

Figure 3 TGA curve of PPMC with $M_{n}$ of $6.94 \times 10^{4} \mathrm{~g} \mathrm{~mol}^{-1}$ (entry 4 , Table 1) conducted under nitrogen at a heating rate of $10^{\circ} \mathrm{Cmin}^{-1} .-\mathrm{O}_{-}$, TG curve; -•-, DTG curve.

Figure 2 Profiles of (a) monomer conversion and (b) $\mathrm{Ln}[\mathrm{Mo}] /[\mathrm{Mt}]$ versus reaction time for the polymerization at $75^{\circ} \mathrm{C}$. Reaction conditions: $(\mathrm{PMC})_{2}(1 \mathrm{~g})$, toluene $(4 \mathrm{ml})$ and Novozym-435 (0.01 g). 


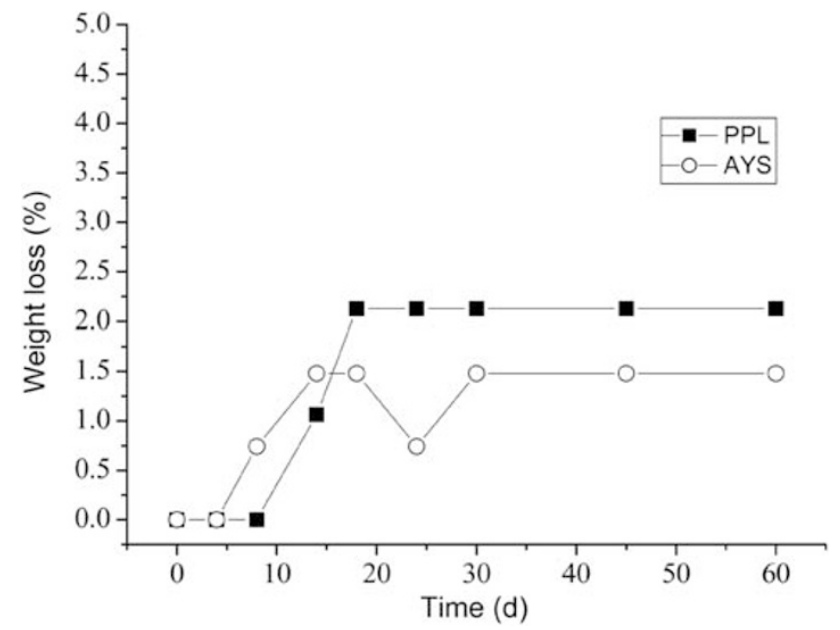

Figure 4 In vitro degradation profile of PPMC in the presence of PPL and AYS lipases.

gravimetric curve of PPMC, weight loss took place in one step, and the curve is characterized by a smooth sigmoid (Figure 3). Similar thermal decomposition behaviors were also reported for the polycarbonates of PTeMC and PHMC (containing four and six methylene groups per unit). Nevertheless, the behavior was different from that of POMC and PDMC (containing 8 and 10 methylene groups per unit), in which the weight loss involves two steps. ${ }^{38-41}$ Another marked disparity is the existence of carbon residue (5-7\% weight\%) after the thermal decomposition of POMC and PDMC, whereas there was no residue in the case of PTeMC, PHMC ${ }^{38-41}$ and PPMC in this study. It is clear that the thermal decomposition of poly(alkylene carbonate)s may not all follow the same mechanism, and the chemical structure exerts a significant influence on their thermal stability and decomposition mechanism.

In this study, the in vitro enzymatic degradation test was conducted in a phosphate buffer solution in the presence of PPL or AYS lipases. Figure 4 shows that the weight loss of PPMC gradually increased and reached a maximum at around $2 \%$. The polymer weight thereafter showed little variation. This finding agrees well with the previously reported finding, in which a similar degradation behavior of PTMC in the presence of lipases was observed. ${ }^{42}$ The result suggests that carbonate groups may not be very sensitive to the enzymatic catalysis from PPL and AYS in the hydrolytic degradation. In contrast, polyesters are more sensitive to the enzyme-induced hydrolytic degradation. ${ }^{43,44}$ The relatively low degradability of PPMC is advantageous in situations in which relatively higher stability is desired.

It is noteworthy that a distinguishing characteristic of aliphatic polycarbonates is that they can be recycled into cyclocarbonates by thermal degradation in vacuo, ${ }^{38}$ which makes them advantageous from a resource-saving and an environmental conservation perspective. In combination with their special chemical and physical properties, this characteristic endows PPMC with great potential for use as a biomaterial, in addition to its use as a plastic. For instance, PPMC may be used to develop soft materials for tissue engineering and as an efficient reservoir for hydrophobic drugs.

Although $\mathrm{Sn}(\mathrm{Oct})_{2}$ catalysis afforded relatively better results with respect to product $M_{\mathrm{n}}$ (up to $1.5 \times 10^{5} \mathrm{~g} \mathrm{~mol}^{-1}$ ), ${ }^{26}$ the enzyme catalysis in this work has a significant advantage in that it does not require high temperature and vacuum, and does not undergo rapid thermal degradation in the polymerization course. Together with the latent catalyst toxicity, these shortcomings limit the practical application of the $\mathrm{Sn}(\mathrm{Oct})_{2}$-catalyzed preparative method. ${ }^{38-41}$ The important role of biosynthetic pathways, such as enzymatic polymerization, has been accepted in the fabrication of biomaterials. Nevertheless, the low catalytic efficiency is known to be the greatest limitation in the industrialization of enzyme catalysis. In this study, lipase catalysis was shown as an effective way to produce high-molecular-weight PPMC under mild conditions. An immobilized lipase of Novozym435 displayed high activity for the ROP synthesis of PPMC. In addition, as reported in many studies, immobilized Novozym435 can retain its catalytic activity even after repeated use. ${ }^{31}$ We believe that with further study, including the rational design of the immobilized lipase carrier and appropriate select of lipase source, PPMCs with much higher $M_{\mathrm{n}}$ can be synthesized. Furthermore, the successful achievement of enzymatic ROP of (PMC) $)_{2}$ makes it possible to manufacture a variety of new materials with well-defined structures through enzymatic copolymerization with other available monomers, such as TMC and $\varepsilon$-caprolactone. Further work is in progress in our laboratory.

\section{CONCLUSION}

PPMC was successfully synthesized by ROP of $(\mathrm{PMC})_{2}$ in toluene under enzyme catalysis. The Novozym-435 lipase exhibited high catalytic activity for the polymerization reaction, resulting in high monomer conversion and $M_{\mathrm{n}}$ of up to $6.0 \times 10^{4} \mathrm{~g} \mathrm{~mol}^{-1}$. A series of experiments were conducted to investigate the influence of reaction parameters, such as monomer concentration and lipase concentration, on the polymerization. We found that there was an optimal enzyme concentration at around $2 \%$, which provided the better result with respect to $M_{\mathrm{n}}$ and monomer conversion. Relatively little polymer degradation occurred during the polymerization. Lipases from porcine pancreas and Candida rugosa exhibited low activity in the in vitro hydrolytic degradation of PPMC. The results indicate that PPMC possessed higher flexibility and tenacity relative to PTMC. The TGAs suggest that the chemical structure of poly(alkylene carbonate)s may exert a significant influence on their thermal stability and decomposition mechanism.

\section{ACKNOWLEDGEMENTS}

This work was financially supported by the National Natural Science Foundation of China (Grant nos. 20304010 and 20874075), the National Key Basic Research Program of China (Grant nos. 2005CB623903 and 2009CB930300) and the Ministry of Education of China (Cultivation Fund of Key Scientific and Technical Innovation Project 707043).

1 Gunatillake, P. A. \& Adhikari, R. Biodegradable synthetic polymers for tissue engineering. Eur. Cells Mater. 5, 1-16 (2003).

2 Pachence, J. M., Bohrer, M. P., Kohn, J., Robert, L., Robert, L. \& Joseph, V. Biodegradable polymers. In Principles of Tissue Engineering 3rd Edn, Academic Press: Burlington, (2007).

3 Seppala, J. V., Helminen, A. O. \& Korhonen, H. Degradable polyesters through chain linking for packaging and biomedical applications. Macromol Biosci 4, 208-217 (2004).

4 Nair, L. S. \& Laurencin, C. T. Polymers as biomaterials for tissue engineering and controlled drug delivery. Biotechnology 102, 47-90 (2006).

5 Gunatillake, P., Mayadunne, R. \& Adhikari, R. Recent Developments in Biodegradable Synthetic Polymers, In Biotechnology Annual Review: Elsevier, (2006).

6 Suyama, T. \& Tokiwa, Y. Enzymatic degradation of an aliphatic polycarbonate, poly(tetramethylene carbonate). Enz. Microbiol. Tech. 20, 122-126 (1997).

7 Pranamuda, H., Chollakup, R. \& Tokiwa, Y. Degradation of polycarbonate by a Polyesterdegrading strain, Amycolatopsis sp. Strain HT-6. Appl. Environ. Microbiol. 65, 4220-4222 (1999).

8 Zhang, Z., Kuijer, R., Bulstra, S. K., Grijpma, D. W. \& Feijen, J. The in vivo and in vitro degradation behavior of poly(trimethylene carbonate). Biomaterials 27, 1741-1748 (2006). 
9 Tinsley-Bown, A. M., Fretwell, R., Dowsett, A. B., Davis, S. L. \& Farrar, G. H. Formulation of poly(D,L-lactic-co-glycolic acid) microparticles for rapid plasmid DNA delivery. J. Control. Release 66, 229-241 (2000).

10 Opanasopit, P., Yokoyama, M., Watanabe, M., Kawano, K., Maitani, Y. \& Okano, T. Block copolymer design for camptothecin incorporation into polymeric micelles for passive tumor targeting. Pharm. Res. 21, 2001-2008 (2004).

11 Al-Azemi, T. F., Kondaveti, L. \& Bisht, K. S. Solventless enantioelective ring-opening polymerization of substituted epsilon-caprolactones by enzymatic catalysis. Macromolecules 35, 3380-3386 (2002).

12 Jérôme, C. \& Lecomte, P. Recent advances in the synthesis of aliphatic polyesters by ring-opening polymerization. Adv. Drug Deliv. Rev. 60, 1056-1076 (2008).

13 Varma, I. K., Albertsson, A. C., Rajkhowa, R. \& Srivastava, R. K. Enzyme catalyzed synthesis of polyesters. Prog. Polym. Sci. 30, 949-981 (2005).

14 Matsumura, S. Enzymatic synthesis of polyesters via ring-opening polymerization. $A d v$. Polym. Sci. 194, 95-132 (2006).

15 Kobayashi, S. \& Uyama, H. In vitro polyester synthesis via enzymatic polymerization. Curr. Org. Chem. 6, 209-222 (2002).

16 Bourissou, D., Moebs-Sanchez, S. \& Martin-Vaca, B. Recent advances in the controlled preparation of poly(alpha-hydroxy acids): Metal-free catalysts and new monomers. $\mathrm{Cr}$. Chim. 10, 775-794 (2007).

17 Uyama, H., Takeya, K. \& Kobayashi, S. Enzymatic Ring-opening polymerization of lactones to polyesters by lipase catalyst: unusually high reactivity of macrolides. Bull. Chem. Soc. Jpn. 68, 56-61 (1995).

18 Müller, S., Uyama, H. \& Kobayashi, S. Lipase-catalyzed ring-Opening polymerization of cyclic diesters. Chem. Lett. 28, 1317-1318 (1999).

19 Matsumura, S., Tsukada, K. \& Toshima, K. Novel lipase-catalyzed ring-opening copolymerization of lactide and trimethylene carbonate forming poly(ester carbonate)s. Int. J. Biol. Macromol. 25, 161-167 (1999).

20 Bisht, K. S., Svirkin, Y. Y., Henderson, L. A. \& Gross, R. A. Lipase-catalyzed ring-opening polymerization of trimethylene carbonate. Macromolecules 30, 7735-7742 (1997).

21 Kobayashi, S., Kikuchi, H. \& Uyama, H. Lipase-catalyzed ring-opening polymerization of 1,3-dioxan-2-one. Macromol. Rapid Commun. 18, 575-579 (1997).

22 Feng, J., Wang, H. F., Li, S. F. \& Zhuo, R. X. Novozym-435 catalyzed ring-opening polymerization of a macrocyclic carbonate. Acta. Polym. Sin. 7, 686-690 (2008).

23 Feng, J., Wang, H. F., Zhang, X. Z. \& Zhuo, R. X. Investigation on lipase-catalyzed solution polymerization of cyclic carbonate. Eur. Polym. J. 45, 523-529 (2009).

24 Namekawa, S., Uyama, H., Kobayashi, S. \& Kricheldorf, H. R. Lipase-catalyzed ringopening polymerization and copolymerization of cyclic dicarbonates. Macromol. Chem. Physic. 201, 261-264 (2000).

25 Yamamoto, Y., Kaihara, S., Toshima, K. \& Matsumura, S. High-molecular-weight polycarbonates synthesized by enzymatic ROP of a cyclic carbonate as a green process. Macromol. Biosci. 9, 968-978 (2009).

26 Su, W., Feng, J., Wang, H. F., Zhang, X. Z. \& Zhuo, R. X. Controllable preparation of poly(alkylene carbonate)s and observation on their structure-related odd-even effect. Polymer 51, 1010-1015 (2010).

27 Tanzi, M. C., Verderio, P., Lampugnani, M. G., Resnati, M., Dejana, E. \& Sturani, E. Cytotoxicity of some catalysts commonly used in the synthesis of copolymers for biomedical use. J. Mater. Sci. Mater. Med. 5, 393-396 (1994).
28 Feng, J., He, F. \& Zhuo, R. X. Polymerization of trimethylene carbonate with high molecular weight catalyzed by immobilized lipase on silica microparticles. Macromolecules 35, 7175-7177 (2002).

29 Kricheldorf, H. R., Lee, S. R. \& Weegen-Schulz, B. Polymers of carbonic acid, 12. Spontaneous and hematin-initiated polymerizations of trimethylene carbonate and neopentylene carbonate. Macromol. Chem. Phys. 197, 1043-1054 (1996).

30 Matsumura, S., Tsukada, K. \& Toshima, K. Enzyme-catalyzed ring-opening polymerization of 1,3-Dioxan-2-one to poly(trimethylene carbonate). Macromolecules $\mathbf{3 0}$, 3122-3124 (1997).

31 Albertson, A. C. \& Sjoling, M. Homopolymerization of 1,3-dioxan-2-one to high molecular weight poly(trimethylene carbonate). J. Macromol. Sci., Part A. 29, 43-54 (1992).

32 Kricheldorf, H. R. \& WeegenSchulz, B. Polymers of carbonic acid. XIV. High molecular weight poly(trimethylene carbonate) by ring-opening polymerization with butyltin chlorides as initiators. J. Polym. Sci., Polym. Chem. 33, 2193-2201 (1995).

33 Matsumura, S., Mabuchi, K. \& Toshima, K. Novel ring-opening polymerization of lactide by lipase. Macromol. Symp. 130, 285-304 (1998).

34 Ritsuko, N., Jun-ichi, S., Meenakshi, G., Michihiko, A., Mitsuru, U. \& Kazuhiko, T. Synthesis of ultra high-molecular-weight polycarbonate. Polym. Adv. Technol. 11, 727-732 (2000).

35 Adam, K., Andrzej, D. \& Stanislaw, P. Kinetics and mechanism of cyclic esters polymerization initiated with tin(II) octoate, 1. Polymerization of $\varepsilon$-caprolactone. Macromol. Rapid. Commmun. 19, 567-572 (1998).

36 Gross, R. A., Kumar, A. \& Kalra, B. Polymer synthesis by in vitro enzyme catalysis. Chem. Rev. 101, 2097-2124 (2001).

37 Zhu, K. J., Hendren, R. W., Jensen, K. \& Pitt, C. G. Synthesis, Properties, and Biodegradation of Poly(1,3-trimethylene carbonate). Macromolecules 24, 1736-1740 (1991).

38 Kricheldorf, H. R., Malhle, A. \& Lee, S. R. Polymers of carbonic acid-19. High molecular weight poly(octamethylene carbonate) by ring-opening polymerization with $\mathrm{BuSnCl}_{3}$ or SnOct 2 . New Polym. Mater. 5, 25-34 (1996).

39 Kricheldorf, H. R. \& Mahler, A. Polymers of carbonic acid. XVII. Polymerization of cyclobis(tetramethylene carbonate) by means of $\mathrm{BuSnCl}_{3}$ and $\mathrm{Sn}(\mathrm{II}) 2$-ethylhexanoate. J. Polym. Sci. Part A: Polym. Chem. 34, 2399-2406 (1996).

40 Kricheldorf, H. R. \& Mahler, A. Polymers of carbonic acid 18: polymerizations of cyclobis(hexamethylene carbonate) by means of $\mathrm{BuSnCl}_{3}$ or $\mathrm{Sn}(\mathrm{II}) 2$-ethylhexanoate. Polymer 37, 4383-4388 (1996).

41 Kricheldorf, H. R., Mahler, A. \& Lee, S. R. Polymers of carbonic acid. 20. High molecular weight poly(decamethylene carbonate) by ring-opening polymerization initiated with $\mathrm{BuSnCl}_{3}$ or SnOct 2 . J. Macromol. Sci. Polym. Chem. 34, 417-428 (1997).

42 Du, L. C., Meng, Y. Z., Wang, S. J. \& Tjong, S. C. Synthesis and degradation behavior of poly(propylene carbonate) derived from carbon dioxide and propylene oxide. J. Appl. Polym. Sci. 92, 1840-1846 (2004)

43 Nakayama, A., Kawasaki, N., Aiba, S., Maeda, Y., Arvanitoyannis, I. \& Yamamoto, N. Synthesis and biodegradability of novel co-polyesters containing $\gamma$-butyrolactone units. Polymer 39, 1213-1222 (1998).

44 Nakayama, A., Kawasaki, N., Maeda, Y., Arvanitoyannis, I., Aiba, S. \& Yamamoto, N. Study of biodegradability of poly( $\delta$-valerolactone-co-L-lactide)s. J. Appl. Polym. Sci. 66, 741-748 (1997). 